\title{
Launching the AquaMAV: Bioinspired design for aerial-aquatic robotic platforms
}

\author{
R. Siddall and M. Kovač \\ Department of Aeronautics, Imperial College London, United Kingdom \\ E-mail: r.siddall13@imperial.ac.uk, m.kovac@imperial.ac.uk
}

\begin{abstract}
.
Current Micro Aerial Vehicles (MAVs) are greatly limited by being able to operate in air only. Designing multimodal MAVs that can fly effectively, dive into the water and retake flight would enable applications of distributed water quality monitoring, search and rescue operations and underwater exploration. While some can land on water, no technologies are available that allow them to both dive and fly, due to dramatic design trade-offs that have to be solved for movement in both air and water and due to the absence of high-power propulsion systems that would allow a transition from underwater to air. In nature, several animals have evolved design solutions that enable them to successfully transition between water and air, and move in both media. Examples include flying fsh, flying squid, diving birds and diving insects. In this paper, we review the biological literature on these multimodal animals and abstract their underlying design principles in the perspective of building a robotic equivalent, the Aquatic Micro Air Vehicle (AquaMAV). Building on the inspire-abstract-implement bioinspired design paradigm, we identify key adaptations from nature and designs from robotics. Based on this evaluation we propose key design principles for the design of successful aerial-aquatic robots, i.e. using a plunge diving strategy for water entry, folding wings for diving efficiency, water jet propulsion for water take-off and hydrophobic surfaces for water shedding and dry flight. Further, we demonstrate the feasibility of the water jet propulsion by building a proof of concept water jet propulsion mechanism with a mass of 2.6 grams that can propel itself up to $4.8 \mathrm{~m}$ high, corresponding to 72 times its size. This propulsion mechanism can be used for AquaMAV but also for other robotic applications where high power density is of use, such as for jumping and swimming robots.
\end{abstract}

Keywords: multimodal locomotion,aquatic micro aerial vehicles, jump-gliding 


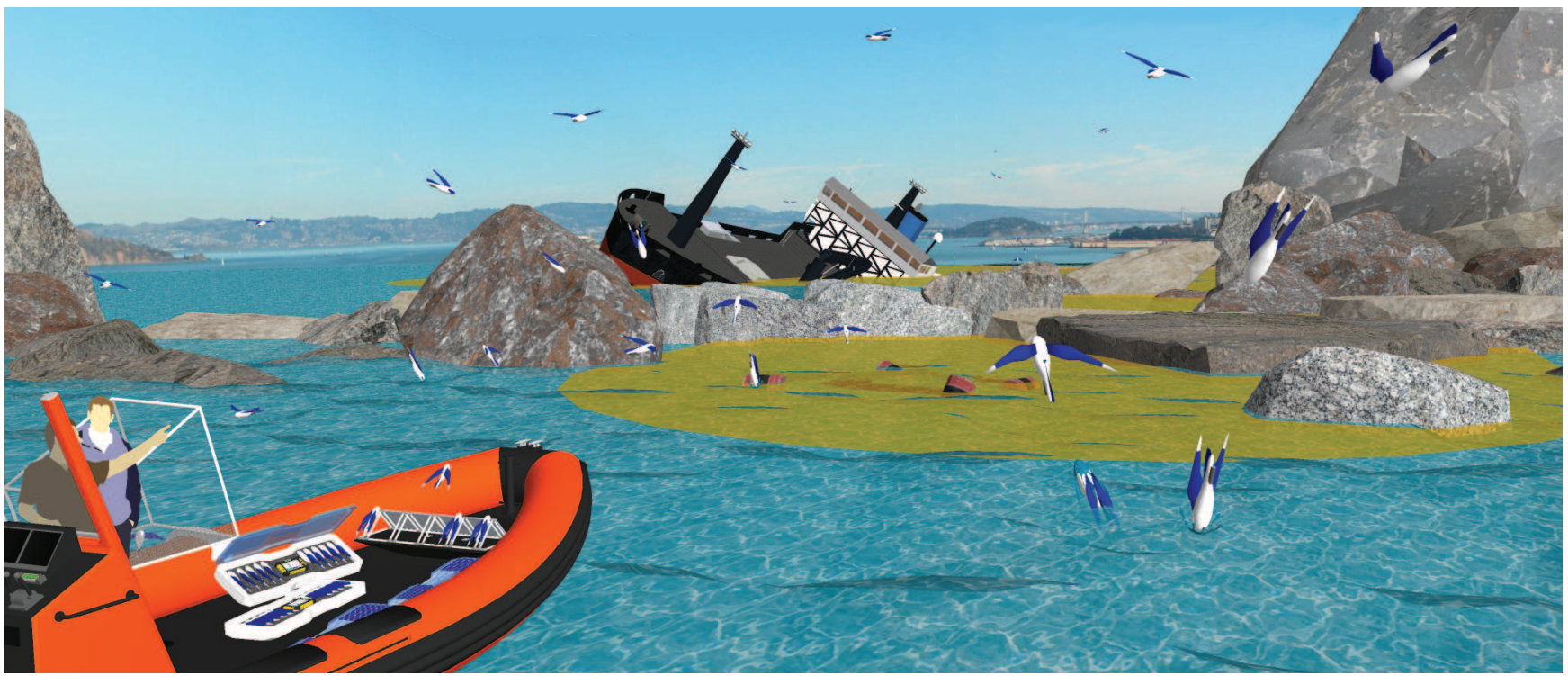

Figure 1: Artistic impression of swarm-deployed AquaMAVs mapping a toxic spill.

\section{Introduction}

Most animals use different forms of locomotion to move through a varied environment. This allows them to adapt to find food, escape threats or migrate, while minimising their energetic cost of locomotion. To do so, animals must use the same locomotor modules to perform specialised tasks that often have opposed requirements. For example, an animal diving into the water to hunt requires a structure that is as lightweight as possible for efficient flight, whilst still being structurally strong when impacting the water's surface. The complexity of biological systems makes them difficult to replicate artificially, but meeting the demands of two modes of locomotion in a single robotic system has been done. Bioinspired robots have been presented that can both fly and move on land, either by jumping or by walking [1-5]. Other robots take cues from amphibious locomotion in nature and can move on land and in water [6-8].

These systems demonstrate both the feasibility and the efficacy of multimodal robotics, and outperform robots with only one locomotion mode. The vehicles have together covered motion in water, land and air, but no robot can move in both air and water, and transition between the two. A robot capable of aerial-aquatic locomotion could play an effective role in disaster relief after floods or tsunamis, where the presence of water and debris will severely limit the operation of conventional vehicles. The potential of robotic systems for use in emergencies was highlighted by recent events such as the Fukushima nuclear accident [9], the response to Hurricane Wilma [10], and the Deepwater Horizon explosion.

In these situations, an MAV can travel rapidly to a target and return aerial footage, but would be unable to land and conserve power, or enter constrained areas such as flooded buildings. On the other side of the spectrum, a purely aquatic robot is not able to pass over obstacles in the water, and cannot take flight for rapid travel over long distances. Having a robot that can travel in air, move underwater and transition back to flight would greatly improve search and rescue capabilities.

An aerial-aquatic vehicle would also have great potential as a sample collection or observation tool for oceanography research, a field in which air-launched underwater vehicles are already sought after [11, 12]. Research has already demonstrated the effectiveness of combining aerial and aquatic robotic operation by coordinating separate systems as a team for the monitoring of coral reefs [13], with an MAV using aerial video footage to guide and augment close observation by an aquatic vehicle. Murphy et al. [10] also found that use of the MAV provided a more effective communication relay with the surface vehicle.

To the best of the author's knowledge, no vehicle currently exists with the capability to move both in the air and beneath the water. The goal of this paper is therefore to offer designers a critical examination both of the biological apparatus used to achieve aerial aquatic locomotion, and a sample of technology relevant to the development of an aerial-aquatic vehicle. The paper begins with an brief explanation of the challenges of aerialaquatic locomotion, to provide context to the remainder of the text. To conclude the paper, we use the inspireabstract-implement bioinspired design paradigm [14] to propose a bioinspired implementation strategy for the development of an efficient aerial-aquatic vehicle: the AquaMAV. To enhance discussion of these proposals, a brief proof-of-concept experiment has also been included. 

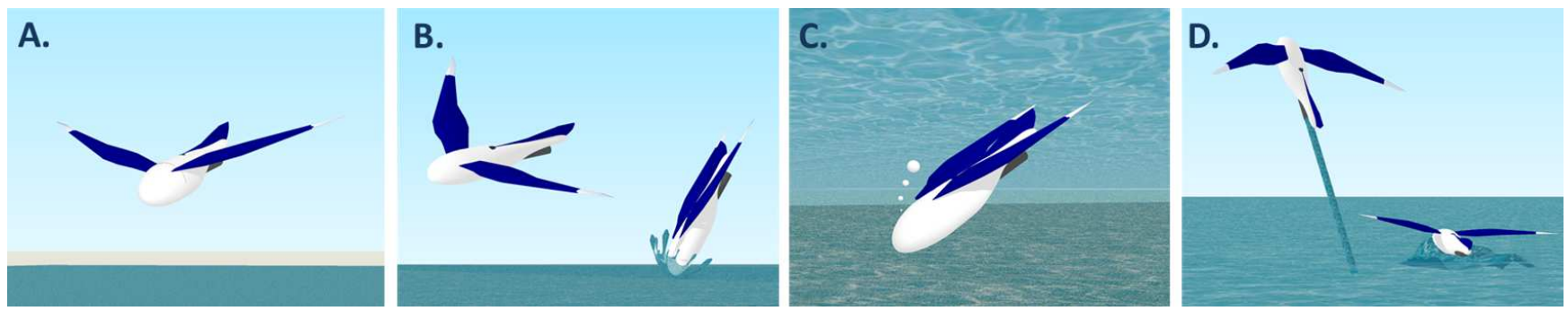

Figure 2: Every stage of an aerial-aquatic mission poses different key challenges for an AquaMAV: (A) Dry Flight, (B) Water Entry, (C) Submerged Movement and (D) Water Exit.

\begin{tabular}{|l|l|}
\hline Mission Phase & Design Challenges \\
\hline Dry Flight (figure 2.A) & Low energy flight, low weight, robustness and stability \\
Water Entry (figure 2.B) & Accurate sensing and control (soft landing) or high impact loads (direct dive) \\
Submerged (figure 2.C) & Deep dive for underwater exploration, low buoyancy, waterproofing and autonomous navigation \\
Water Exit (figure 2.D) & High power density (direct launch) or low surface drag (taxiing takeoff) \\
\hline
\end{tabular}

\section{Challenges}

Transitioning between flying and swimming presents several key design challenges. To analyse them, it is helpful to examine the robot's mission in the context of distinct mission phases (figure 2): First the robot has to perform high efficiency flight, then must transition from air to water when at a target. After transition, it must spend a period moving beneath the surface for water sampling and video footage, before transitioning back to flight from the water.

\subsection{Dry Flight}

The key challenge when in flight is the minimisation of power requirements. This is achieved by maximising the aerodynamic efficiency of the vehicle, which becomes more difficult at the small scale. Micro Aerial Vehicles typically operate in the Reynolds number range $10^{4}-10^{5}$, and at these low flight Reynolds numbers the aerodynamic efficiency of flight is reduced due to increased viscous effects, and air perturbations will have a much more significant effect on the vehicle [15]. Furthermore, the design constraints of flight must be satisfied simultaneously with those imposed by the need to swim. These additional constraints come from the need for dual propulsion modes, a stronger superstructure and waterproof design, all of which add to the flight mass.

Materials considerations for the wings will be essential, not only for the minimisation of structural mass. Selecting materials to add flexibility to the wing structure also offers many enhancements for low Reynolds number vehicles, from aerodynamic increases by allowing both passive and active adapting of wing morphology [16], to structural increases by improving durability [17].

\subsection{Water Entry}

The challenges associated with entering the water depend on the strategy for transition. Plunge diving directly through the surface carries over flight momentum into the water, and can allow depths to be reached rapidly. However, in order to do so a vehicle must be as slender and streamlined as possible to minimise impact loads. Diving impact loads have been found to scale approximately with the square of impact velocity [18], and result largely from the accelerated mass of water on impact. The added mass will scale with the body cross sectional diameter to the third power (an oversimplification, but one that highlights the importance of minimising cross section during impact). This makes effective, deep diving highly impractical for fixed-wing aircraft, and no animal attempts to dive directly through the surface without folding or morphing its wings.

A body impacting at too shallow an impact angle will experience a large bending moment, and if the dive has insufficient momentum it may rebound from the water surface rather than fully penetrating, due to the impact pitching moment and rapid deceleration [18, 19]. For dives at shallow angles, the eccentricity of the impact load also has a tendency to flip a vehicle, which is a significant problem for soft floatplane landings.

Alternatively, a vehicle can perform a soft landing, whether by gradual descent or deep stall just above the surface. This approach reduces structural requirements and may mean folding wings are not necessary, but an additional system for underwater propulsion is then needed, and the robot cannot benefit from flight momentum when diving into water. This entry strategy will also require more accurate control capability and sensing of altitude, which adds mass and complexity. 


\subsection{Submerged Movement}

Once the vehicle is in the water, it must contend with resistance from buoyancy and drag increased by several orders of magnitude, due to the increased density and viscosity of water compared to air. The benefits of reducing buoyancy for efficient swimming must be traded against low weight for efficient flying. For non-zero buoyancy, the centre of volume as well as the vehicle's hydrodynamics will determine its stability, which will be important if a plunge dive and passive, buoyancy driven ascent is desired. As the robot travels deeper, hydrostatic pressure loads will also become significant, and place harsher requirements on the robot's structure and the waterproofing of electronic components. The limited propagation of electromagnetic waves in water [20] will also make remote control of microrobots highly difficult, forcing the vehicle to instead rely on autonomous control.

\subsection{Water Exit}

The key challenge here is building up speed for flight. However, most MAVs in regular use are not launched under their own power, but rely on gravity or being thrown in order to generate their initial flight speed. This difficulty is only compounded by aquatic locomotion, where hydrodynamic drag limits the speeds achievable [21], especially at the surface, where additional effects such as wave and spray drag can increase resistive forces by 5 times their value when fully submerged [22]. Wave drag is caused by the formation of a wave pattern around a body, the wavelength of which increases with speed. As the wavelength exceeds the body's length, the stern begins to sit in the wave trough, and the vehicle is forced to climb its own bow wave, dramatically increasing power requirements and restrict maximum speed relative to body length.

Furthermore, the takeoff power requirements will be significantly increased by the added weight of water [23], which must be shed as quickly as possible. Wind driven surfaces waves can also be a significant problem for small scale aerial-aquatic vehicles; just as the relative size of gust perturbations increases for micro scale flight, so does the relative wave height for micro scale surface swimming. Waves passing across the vehicle can immerse lifting surfaces and cause the vehicle to crash, and for a taxiing takeoff, the vehicle may then have to move in the same direction as wave propagation, which will require additional sensors.

\subsection{Wet Flight}

Once the vehicle has left the water with sufficient velocity, it then needs to return to efficient flight. To do so it will be important to shed any water weight picked up during swimming. The amount retained surface water will depend on the surface's properties, but will broadly

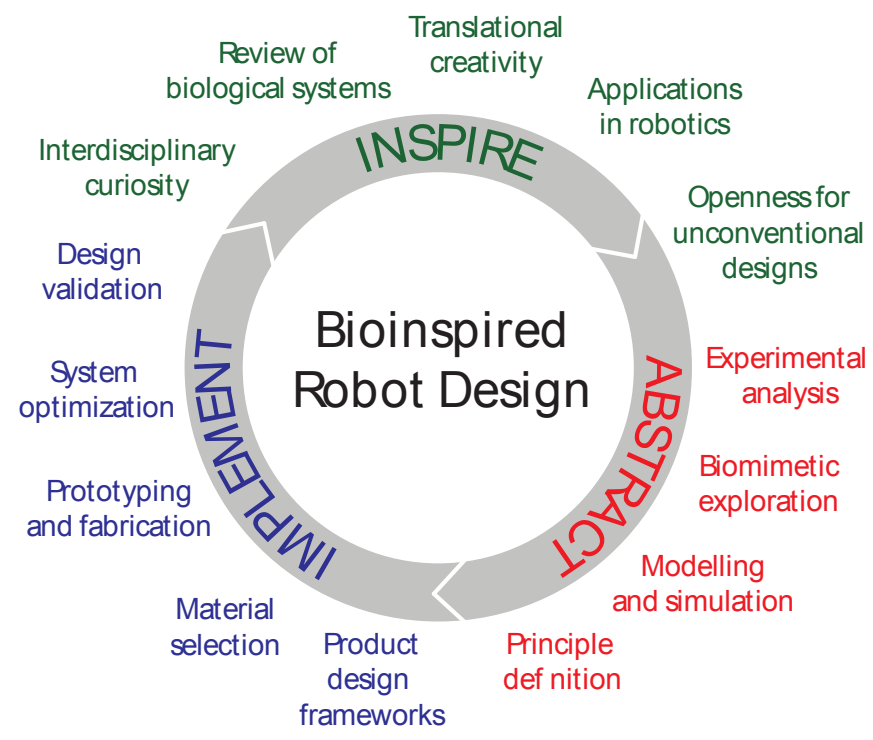

Figure 3: The Inspire-Abstract-Implement paradigm for bioinspired robot design. Figure reproduced from [14].

scale with surface area. Because surface area to volume ratio decreases with size, this may represent a significant barrier to the minitaturisation of aerial-aquatic robots.

Flight trajectory planning will also be important, as the ground effect can be exploited near the water surface to reduce induced drag, which has been shown to alter maximum range gliding flight paths [24]. However, water waves and spray will restrict the minimum flying height and affect the local airflow near the surface which will create flight perturbations, so flight must be robust in order to do this.

\section{Biological Design Strategies}

For animals, one of the biggest evolutionary pressures is the need to reduce their energetic cost of locomotion, while still being capable of moving through unstructured and varied terrain. A myriad of animals have evolved a seamless transition between powered locomotion in water and air, and move through both media with the efficiency required to forage and migrate effectively. Bioinspiration is a particularly powerful tool in the design process, where conventional, single-mode design strategies become less applicable. This is especially the case for the design of microrobots, where energy and power density is limited, and trasnport efficiency is of paramount importance.

However, bioinspiration should not entail the blind copying of the morphology or behaviour of natural systems, and animals face different design constraints to their robotic counterparts. Evolution itself moves towards sufficient rather than optimal design, and the evolutionary pressures faced by animals and robots are not always the same. For example, many of the features common in gliding vertebrates, such as a dorsoventrally flattened body 

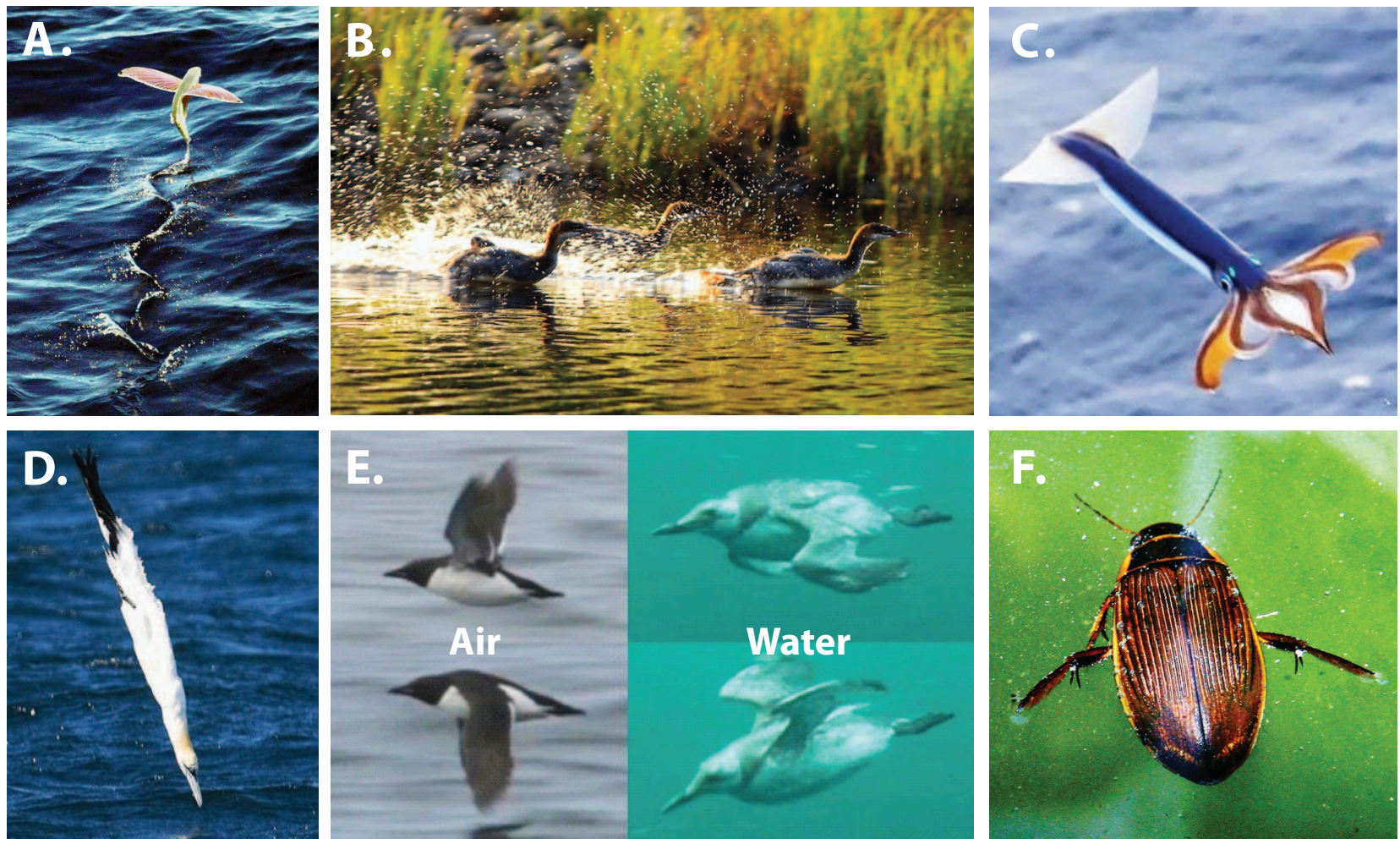

Figure 4: Strategies for aerial-aquatic locomotion: (A) Two stage transition: Flying Fish, (B) Hydroplaning: Ducks, (C) Jet propulsion: Flying Squid, (D) Plunge diving: Northern Gannet, (E) Morphing wings: Common Guillemot, (F) Foot propulsion: Great Diving Beetle. Images used with permission from: US NOAA (A), Cappi Thompson (B), Kouta Muramatsu (C), David Tipling (D), Lock et al. [25] (Unaired BBC footage) (E) and Warren Photgraphic $(F)$

or webbing between limbs may be used by other animals for display or disguise, rather than any aerodynamic purpose [26]. Because of this, it is important not to simply duplicate nature, but to examine and abstract key principles which guide practical, optimised design.

In this paper, we adopt the Inspire-AbstractImplement paradigm for bioinspired robot design (figure 3) [14], and focus on the Inspire and Abstract phases of the process, examining and evaluating the performance of animals with a view to advancing robotics. For a detailed description of this bioinspired design strategy, interested readers can refer [14].

\subsection{Flying Fish}

Over 40 species of marine fish have evolved the ability to perform extended flights above the water's surface. These animals leap from the water's surface and glide on enlarged pectoral fins (figure 4.A), and are capable of spending over 40s airborne [27]. Beneath the water the oceanic flying fish (family Exocoetidae) are conventional swimmers, with their pectoral fins folded against their body. But when deployed in flight, these fins form high performance [28] membranous wings. The wing flexibility also allows the fish's body to rotate relative to its wings, providing further stability [29], particularly during emergence [2]. The wing itself has pointed tips, which will reduce induced drag without increasing the root bending moment (which must be supported by muscle tension) [30]. The wing membrane is supported by many cartiliginous fin rays, with an L-shaped cross section [27]. This structure will enhance wing stiffness to weight ratio, but also allows tesselation on folding. The deployed wing is also given a non-smooth surface by this structure, which may also offer aerodynamic performance benefits in the low Reynolds number range [15].

Underwater, a typical $30 \mathrm{~cm}$ flying fish cruises at low speed $(1 \mathrm{~m} / \mathrm{s})$, but is capable of burst swimming at up to $10 \mathrm{~m} / \mathrm{s}$ when leaving the water. However, gliding speeds are in the range $15-20 \mathrm{~m} / \mathrm{s}$ and the fish are better able to reach these high speeds in air, where drag is lessened $[27,31]$. Additional speed is then gained through a 'taxiing' phase, with wings deployed clear of the water to balance body weight with lift, while only the caudal fin remains submerged, and can continue to propel the animal (figure 4.A). This also enables prolonging of flights by intermittently taxiing and 'topping up' airspeed, and allows the fish to take more advantage of the ground effect [24]. As is common with most fish, their skin secretes a mucus which is viscosity-reducing, a surfactant and hydrophobic [32]; features which can reduce drag, ease wing unfolding [27] and help to shed water in flight. 


\subsection{Flying Squid}

The only fully aquatic animals displaying what can be considered true powered flight are the flying squid (several species mainly from the family Ommastrephidae, figure 4.C). Flying squid have two sets of deployable wings. Their rear, main lifting surface is formed by their tentacles, splayed apart to stretch a membrane, and the forward wing is formed by a pair of fins, which are also used for flapping propulsion underwater at low speeds [33]. The forward fins of flying squid species have a higher aspect ratio than those of non-flying species, which is likely a result of adapting for flight [31].

To power their flight, these animals use a pressurised water jet to provide thrust in the air [34]. This airborne jet provides the fish with a final momentum boost, allowing them to perform an aerial jump-glide in a similar fashion to flying fish. These flights can last for 7-8 seconds [35] (a full power jet expulsion by a similarly sized quid takes around $200 \mathrm{~ms}$ [36]) at peak speeds of up to $11 \mathrm{~m} / \mathrm{s}$ [37]. When swimming underwater, jet propulsion is fundamentally less efficient than locomotion through the beating of fins and tails seen in teleost fish and cetaceans, due to the larger mass of water that must be moved for propulsion. However, the thrust response of jet propulsion is much faster, which gives squid advantages in escape and manoeuvreability [38]. Furthermore, the jetting mechanism is uniquely applicable to aerialaquatic missions because it can provide equal thrust in both water and air.

The squid's water jet is driven by contractions of its mantle cavity, which can undergo volume changes of $400 \%$ during a full power jet cycle. Driving the jet with radial contractions maximises the volume of water a squid can expel relative to its size, and reduces the internal flow velocity and associated viscous losses (relative to a piston driven expulsion, for example). During the jetting phase, the water pressure within the squid mantle reaches around $25 \mathrm{kPa}$ in a typical squid with a $21 \mathrm{~cm}$ mantle length [36]. The squid's cavity muscle cannot provide sufficient power over its full contraction range, and so additional elastic energy is stored in collagen fibres as the cavity is expanded and filled with water [39]. The outflow nozzle of the jet is also muscular, and the squid can adapt its geometry during jetting to optimise propulsive efficiency. This also allows it to vector its jet thrust to steer.

As muscular hydrostats, the wing muscle tension required during flying may limit the duration of squid flights [37], and the animals are observed to actively brake and fold their wings to return to the water [40], diving in a streamlined, nose forward configuration. The squid's main wing is formed by soft tentacles, which could allow the squid to adapt its planform shape. It is suggested that the squid has 'chosen' a near elliptical planform [31], which would minimise induced drag, but shape adjustments could reduce the wing bending moment [30], suggesting that muscle tension may not be limiting in flight. However, apsects of the planform shape could also be a structural artifact of stretching the wing membrane to maximise wing area.

\subsection{Aquatic Birds}

A wide variety of flying birds can also move beneath the water. To takeoff again, many birds will be able to lift themselves from the water purely by flapping, but many heavier birds that have adapted for swimming must first accelerate. To avoid wave drag penalties while doing this, birds will lift themselves out of the water as they accelerate, and hydroplane on the water surface through a combination of flapping and foot propulsion [41]. This can be seen in figure $4 . \mathrm{B}$, in which the suppression of wave drag is made apparent by the absence of a bow wave in front of the birds. However, the large amount of spray scattered by the birds also gives an indication of how energetic a process this is. Most aquatic birds execute this kind of taxiing takeoff, with foot propulsion supplementing their flapping power. Where diving birds differ the most is the manner in which they move below the surface. Broadly speaking, underwater hunting methods in birds can be divided into plunge diving directly from flight, and pursuit diving, in which underwater locomotion is initiated from a stationary position on the water surface.

\subsection{Plunge Diving}

Gannets (genus Morus) have one of the more spectacular strategies for catching prey below the water surface. These birds plunge dive from the air at heights of up to $30 \mathrm{~m}$, and entry speeds of up to $24 \mathrm{~m} / \mathrm{s}$ [42]. To maximise their penetration depth, gannets have a long slender body, and wings that can be swept fully backward to minimise their cross section when entering the water (figure 4.D) . They also have subcutaneous air sac structures, pressurised through connection to the lungs. These structures streamline their bodies, cushion impact and provide some means of buoyancy control [43]. Recordings from data loggers attached to the backs of diving gannets record no measurable impact deceleration at a sampling rate of $32 \mathrm{~Hz}$, as argued by Ropert-Coudert et al. [44].

Interestingly, a recent computational simulation of gannet water impact [18] has predicted high impact decelerations (up to $23 \mathrm{~g}$ for a $24 \mathrm{~m} / \mathrm{s}$ dive) with force peaks lasting on the order of $0.1 \mathrm{~s}$, which should be measurable by the loggers in [44]. The simulation treats the gannet as rigid, and the disparity could be accounted for to some extent by the gannet's air structures and feathers. The feathers of the gannet are also both air filled and hydrophobic, so will entrain and release an air layer around the bird's body during a dive, likely to an extent that was not captured in [18]. This has been suggested as a source of drag reduction through air lubrication in penguins [45], 
but it should also be noted that [18] predicts a minimal contribution to impact force from skin friction. Another consideration is the fact that the gannet will be exceeding the surface cavitation speed on impact [46], though well below the speed to form a natural supercavity.

While capable of some swimming, the birds generally achieve depth purely through the momentum of their dive [47]. When they have reached their desired depth, they redeploy their wings as brakes, before allowing buoyancy to propel them back to the surface. While this strategy of minimal swimming limits the birds' underwater range, it is noteworthy that compared to other diving animals the gannet has a much higher foraging success rate in terms of food energy per unit time, something necessitated by the energy required to remain airborne whilst seeking a target. These birds are more efficient flyers than most aquatic birds, with large, high aspect ratio wings for efficient loitering whilst seeking a dive target. The downside of such large wings comes when attempting to leave the water, where the flapping stroke length is constrained. Gannets on the surface of rough seas often must wait for the water to calm before they are able to takeoff [48]. To compensate for their limited flapping power at the surface, the birds takeoff into the wind whilst holding their wings aloft to generate initial lift, and use dynamic soaring flying techniques, gaining altitude using air currents deflected by surface waves.

Plunge diving behaviour is not limited to gannets and boobies (Sulidae), but is also exhibited to a less striking extent in smany other bird families, such as kingfishers (Alcidinae) [47], pelicans (Pelicanidae) [49] and some shearwaters (Procellariidae) [50]. These birds do not plunge as deeply, and the shearwaters rely more heavily on propulsion from their wings to forage [50].

\subsection{Pursuit Diving}

Auks (Alcidae), particularly guillemots (genus Uria) are almost equally at home moving in air or in water. These birds swim by flapping in both media, while adapting their wing morphology dynamically to their environment. Flight favours large wing areas, while underwater flapping is better achieved with smaller, shorter wings [51] and to maximise their efficiency guillemots will morph their wings to a highly swept, lower aspect ratio configuration when swimming (figure 4.E) [52]. A consequence of adapting smaller wings for flapping underwater is an increased wing loading. A Common Guillemot (Uria aalge) weighs $0.9 \mathrm{~kg}$ and has a wing loading of around $170 \mathrm{~N} / \mathrm{m}^{2}$. This can compared to $55 \mathrm{~N} / \mathrm{m}^{2}$ for a plunge diving Brown Booby (Sula leucogaster) of the same mass, or an expected $100 \mathrm{~N} / \mathrm{m}^{2}$ for a $0.9 \mathrm{~kg}$ flying fish. The high wing loading impedes the birds' manoeuverability and takeoff performance, forcing them to flap at much higher rates and fly at high speeds.

Other birds such as cormorants, grebes, ducks and loons dive with folded wings, propelled by their feet. Cormorants (Phalacrocoracidae) are some of the most capable foot propelled divers, and are widely studied. Adaptations in these birds' bone and muscle structure make their specific buoyancy around half that of other flying seabirds [53], and cormorants are able to achieve neutral buoyancy by swimming to depths greater than $50 \mathrm{~m}$, at which point the air in their feathers and lungs is sufficiently compressed by water pressure [54]. At depths where they are still positively buoyant, cormorants use an intermittent 'burst and coast' swim pattern to counteract upthrust efficiently while swimming [55]. They do not dive from flight, but will execute a half dive by leaping in an arc from the water surface to achieve some initial momentum.

Buoyancy control is important to diving birds because they are obliged to carry with them a certain volume of air when diving. This is for both insulation and respiration, as well as the need for dry plumage when returning to flight. As mentioned previously, in peguins (Spheniscidae) the trapped air compressed beneath feathers can escape during ascent from a dive, which may reduce drag by as much as $70 \%$ through the creation of a lubricating air film [45]. This allows the birds to leap onto high vertical ice shelves from the water. However, the presence of feathers is overall likely to constitute a drag penalty in steady submerged swimming [56] for thermal insulation, and the ability to fly efficiently [57]. While most pronounced in cormorants, pursuit diving flying birds have all evolved less waterproof plumage than their non-aquatic counterparts to some degree, and many of these birds must dry their wings on land before attempting long flights [58]. The air retaining features of feathers are a result of their hydrophobic microstructure, which is also of great importance for flight from water, where takeoff power requirements in birds can be increased by around $30 \%$ with a $10 \%$ mass increase from retained water [23].

\subsection{Diving Insects}

Many insects are able to swim beneath the water, and some have also retained their wings and can still fly in air. Beneath the water, diving beetles (Dytiscidae) use their legs to kick, with air trapped beneath their wings for breathing (figure 4.F)[59]. Without the soft, compressible air retaining structures of birds, the trapped air forces them to constantly swim downward to counter buoyancy. Across the several thousand known species of diving beetle, a broad range of morphologies exist. These differences can be related to the relative coverage of their habitat by water, and that water's flow speed. Fast swimming beetles exhibit slender, more streamlined body shapes, and exoskeletons with fewer protuberances, to reduce turbulence [60].

Dragonflies (Anisoptera), arguably one of the natural world's most capable flyers, lay their eggs underwater 

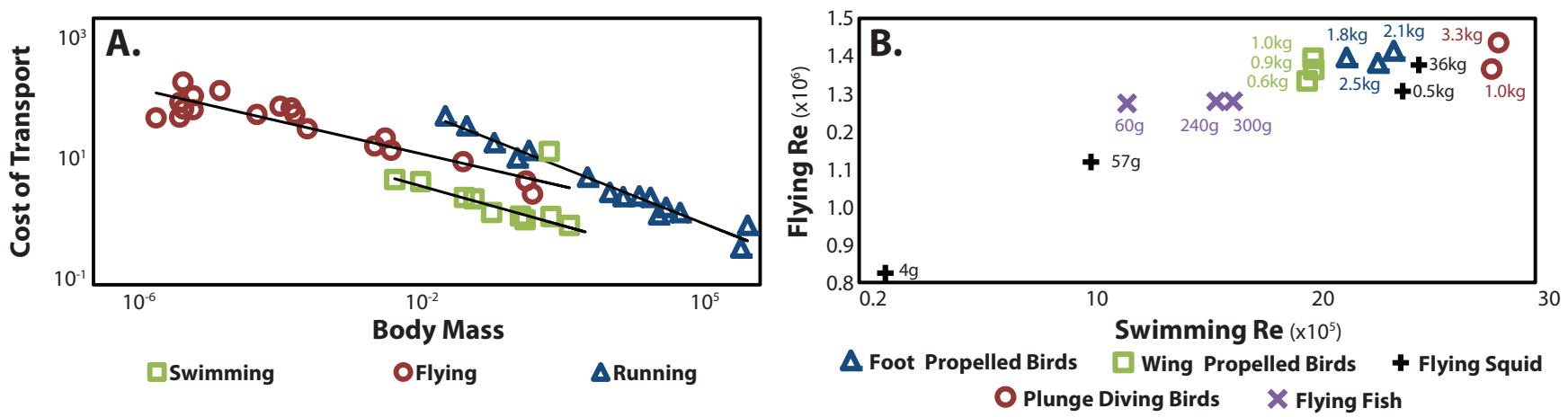

Figure 5: (A) The metabolic costs of different locomotion strategies (reproduced from [51]). (B) Average airborne and submerged Reynolds numbers for aerial-aquatic animals, with body mass indicated.

and will dive directly through the surface, but adults are unable to swim and instead rely on crawling along submerged material [61]. While underwater, breathing air trapped by their wing microstructure allows them to remain submerged for hours at a time, but to leave the water, they struggle to free their wings from surface tension and must spend a period drying before further flight. Dragonfly nymphs are fully aquatic, and larger larvae (approximately $50 \mathrm{~mm}$ in length) are able to swim using jet propulsion similar to that of cephalopods. By doing so, the animals can produce pulsed water jet thrust at around $2 \mathrm{~Hz}$, with up to $150 \mathrm{mN}$ amplitude. However, the jetting mechanism is tied to the larval form's underwater breathing apparatus, and is abandoned once the dragonfly metamorphoses into its adult stage [62].

Most insects leave the water by simply climbing out and drying themselves, but several very small species of jumping insect have also adapted to leap from the water's surface. Pigmy mole crickets (around $7 \mathrm{mg}$ mass) are able to leap to around 60 times their own height from the water surface [63], but such small insects are reliant on surface tension to support themselves on the water while static, and do not have any swimming ability.

\subsection{Sizing and Energetics}

In nature, aerial and aquatic animals show marked differences in metabolic costs (figure 5.A). Transport costs in water are reduced because self-weight does not need to be counteracted during motion due to the presence of buoyancy [51]. Figure 5.A also highlights the importance of size as a design consideration, and as size is reduced increased effects from viscosity, surface tension and natural perturbantions act to reduce locomotion efficiency. However, many of the envisaged applications for an aerial-aquatic vehicle (section 1) require a vehicle that can be rapidly transported to an area of interest for deployment, and this will be facillitated by small size and low weight. Smaller robots can also functionally locomote in smaller spaces, which will allow closer observation.

Flight favors low density, while swimming favours neutral buoyancy, and pursuit diving birds lose flying ability as their size increases [64]. The largest auk and cormorant (Pinguinus impennis and Phalacrocorax perspicillatus) were flightless and near flightless respectively. Within a given locomotion strategy, most aquatic animals show little variation in size and speed (figure 5.B). However, squid range in length from $20 \mathrm{~mm}$ to well over $10 \mathrm{~m}$, and flight has been documented in squid ranging from $60 \mathrm{~mm}$ to over $1 \mathrm{~m} \mathrm{[40],} \mathrm{a} \mathrm{variation} \mathrm{in} \mathrm{size} \mathrm{far} \mathrm{sur-}$ passing that of any other aerial-aquatic animal. This suggests a scalability that could make taking inspiration from flying squid highly applicable to robot design.

It has also been suggested that flight in squid and fish offers energetic advantages for migration over aquatic locomotion alone [34]. This is due to the reduced drag in air, and is against the overall trend in figure 5.A. While the subject of contention, this highlights the fact that size is not the only consideration for transport efficiency, and careful selection of locomotion strategy will also be key to AquaMAV design.

\section{Existing Aerial-Aquatic Robots}

While no truly aquatic flying vehicle exists, studies have recently been conducted on the implementation of plunge diving capability into a flying vehicle $[18,65,66]$. Liang et al [66] have developed a testing platform able to fold its wings before diving into the water. However, this device is currently an experimental platform being used to evaluate the requirements for a plunge diving vehicle and does not yet have flight capability.

Flapping propulsion has been demonstrated in many robots, and has many advantages, both in air [67] and in water [68]. Lock et al. [25] used experimental data to develop a model for the effect of wing sizing and morphing on the power requirements in air and water of a guillemot inspired flapping wing robot. This enabled them to propose different 

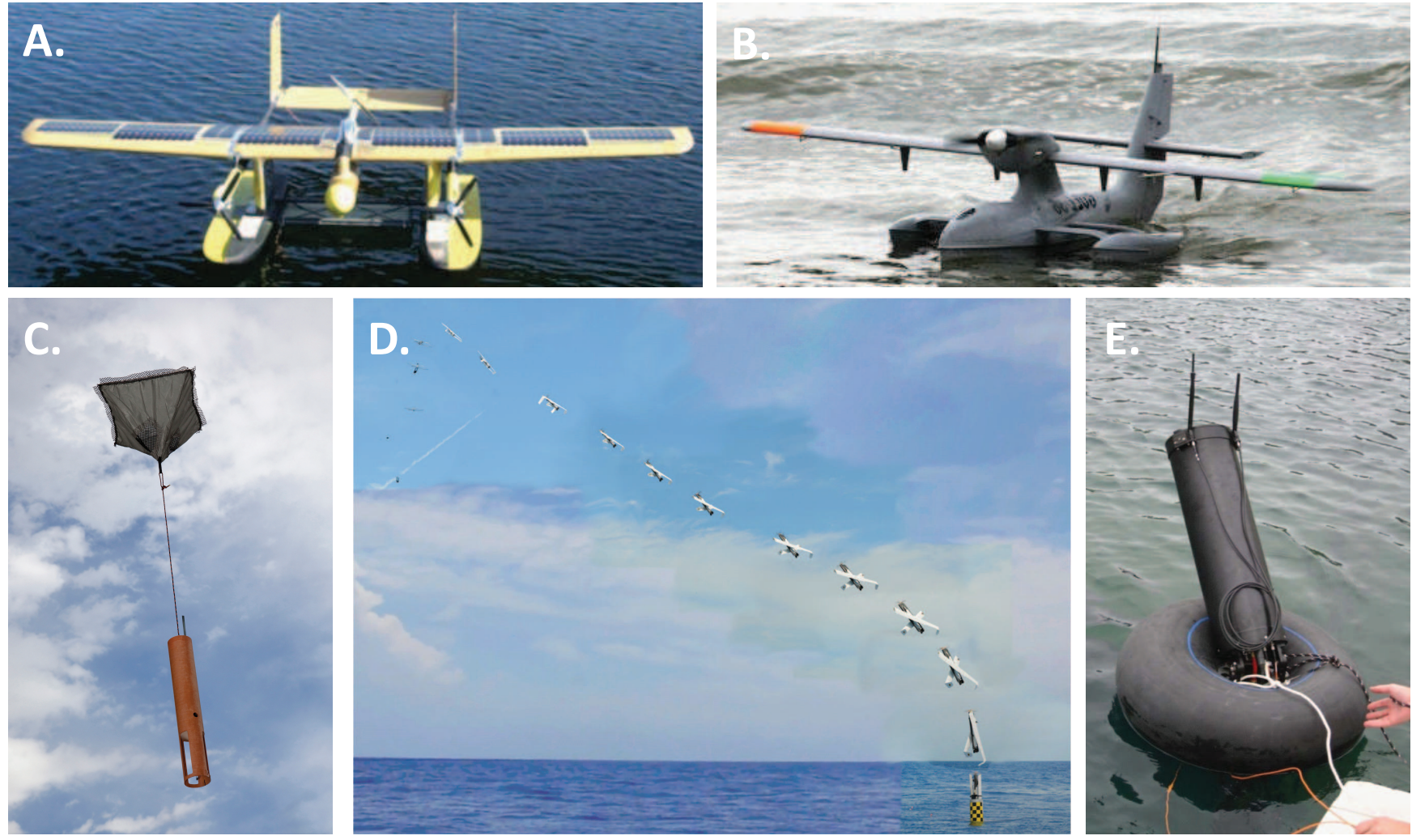

Figure 6: Aerial-aquatic robotics. Aquatic unmanned aerial vehicles: (A) The University of Michigan's 'Flying Fish'and (B) Warrior Aero's 'Gull'. (C) TACMAV underwater MAV launcher. (D) 'Sea Robin' submarine launched UAV launch sequence. (E) Dropsonde air launched atmospheric reconnaissance device.Images used with permission from: University of Michigan (A), Warrior AeroMarine (B), ARA Force Protection (C), US NCAR (E)

optimised geometries depending on the relative amount of time the robot would spend in air and water during a mission, but this work was not developed into a practical robot.

Robotic flapping flight in air currently relies on very light, low inertia wings with high flapping speeds [69], and those wings and their associated actuators would be unsuited to use underwater. Furthermore, the loss of stroke range when floating on the surface would make it highly difficult to take off without pontoons, the use of which would then hugely inhibit submerged movement. We therefore suggest that hybrid flapping propulsion is not an immediately feasible design strategy for an AquaMAV, principally because of the difficulty in making such a system transition between locomotion modes. However, future advances in technology may well make this more feasible.

Many robotic aerial vehicles exist which use the water's surface as an extended runway. Three examples of UAV seaplanes are the Oregon Ironworks 'SeaScout', Warrior Aeromarine's 'Gull' and the University of Michigan's 'Flying Fish' (figure 6.A/B). The former two vehicles are remotely operated, but are able to land and takeoff autonomously, while the Flying Fish is fully autonomous and is designed to operate as a mobile surveillance buoy [70]. All of these aircraft are propeller driven, use a conventional wing layout, execute soft landings and are incapable of fully submersing themselves in the water. They are also well out of the micro scale, all having wingspans of around $2 \mathrm{~m}$. To takeoff, these vehicles rely on highly buoyant pontoons to keep their propellers positioned clear of the water surface, require large landing and takeoff areas and are not able to move through difficult terrain, such as flooded buildings or areas of floating debris.

The Gull UAV (figure 6.A) does have the ability to fold its wings, though this is used for manoeuvering and storage rather than diving. It also is able to exploit surface waves $(0.3 \mathrm{~m}$, or $15 \%$ of its size) at takeoff, using them as ramps. However, this UAV is large in size, and those same waves would be a far bigger impediment to a micro scale vehicle attempting to perform a taxiing takeoff or a shallow descent.

While none of these robots are able to operate beneath the surface, systems do exist for deployment of underwater vehicles from the air. Such systems are reliant on single use, disposable equipment such as parachutes, airbags and discardable wings (figure 6.C). However, the existence of a demand for air launched underwater vehicles [11] is important nonetheless, and a realised AquaMAV would have inherrent capability for air launched aquatic response. 
Table 1: Key design principles from nature and robotics

\begin{tabular}{|c|c|c|c|c|c|}
\hline Animal & Dry Flight & Water Entry & Submerged Movement & Water Exit & Wet Flight \\
\hline $\begin{array}{l}\text { Flying Fish } \\
\text { (Exocoetidae) }\end{array}$ & $\begin{array}{l}\text { Flight in ground effect to reduce } \\
\text { drag [24]. Thin flexible wings } \\
\text { for stall performance and } \\
\text { stability }[28,71] .\end{array}$ & $\begin{array}{l}\text { Wings lie flat against the } \\
\text { body [27]. }\end{array}$ & $\begin{array}{l}\text { Oscillating tail fin propulsion, } \\
\text { swim bladder allows changes in } \\
\text { buoyancy.[51] }\end{array}$ & $\begin{array}{l}\text { Taxiing acceleration } \\
\text { with only propulsive fin } \\
\text { submerged [27]. }\end{array}$ & $\begin{array}{l}\text { Hydrophobic mucus helps } \\
\text { shed water. Intermittent } \\
\text { taxiing to increase speed }\end{array}$ \\
\hline $\begin{array}{l}\text { Flying Squid } \\
\text { (Ommastrephidae) }\end{array}$ & $\begin{array}{l}\text { Water jet propulsion provides } \\
\text { thrust [34]. Elliptical wing to } \\
\text { reduce wing tension [31]. }\end{array}$ & $\begin{array}{l}\text { Fore wings lie flat against } \\
\text { the body. Hind wings } \\
\text { streamlined backward [37]. }\end{array}$ & $\begin{array}{l}\text { Water jet propulsion [72] or } \\
\text { flapping wings/fins [33]. } \\
\text { Intermittent locomotion used to } \\
\text { conserve energy [36]. }\end{array}$ & $\begin{array}{l}\text { High speed leap } \\
\text { followed by water jet } \\
\text { thrust to accelerate [37]. }\end{array}$ & $\begin{array}{l}\text { Flying time limited by } \\
\text { muscle tension and oxygen, } \\
\text { flight is ended deliberately by } \\
\text { air braking and diving.[40] }\end{array}$ \\
\hline $\begin{array}{l}\text { Gannet } \\
\text { (plunge diving) } \\
\text { (Sulidae) }\end{array}$ & $\begin{array}{l}\text { High aspect ratio wings for } \\
\text { efficient loitering.[73] Feathered } \\
\text { wings adapt to wind } \\
\text { perturbations[71]. }\end{array}$ & $\begin{array}{l}\text { Wings swept to } 90^{\circ} \text {, air } \\
\text { sacs cushion impact [43]. } \\
\text { Flight into wind for low } \\
\text { groundspeed and fast dive } \\
\text { response [73]. }\end{array}$ & $\begin{array}{l}\text { Little swimming [47], depth gained } \\
\text { by dive momentum, buoyancy } \\
\text { used for ascent [44]. }\end{array}$ & $\begin{array}{l}\text { Hydroplaning taxiing } \\
\text { by flapping and foot } \\
\text { propulsion. }\end{array}$ & $\begin{array}{l}\text { Water repellent feathers shed } \\
\text { moisture. Foraging upwind of } \\
\text { nest so tailwind aids return } \\
\text { flight, when food and water } \\
\text { add to weight. }\end{array}$ \\
\hline $\begin{array}{l}\text { Cormorant } \\
\text { (foot propelled) } \\
\text { (Phalacrocoracidae) }\end{array}$ & $\begin{array}{l}\text { Relatively high weight } \\
\text { compensated for by large } \\
\text { wings.[74] Feathered wings. }\end{array}$ & $\begin{array}{l}\text { Slowed descent and soft, } \\
\text { floating landing. Short } \\
\text { dive-initiating leap from } \\
\text { the surface. }\end{array}$ & $\begin{array}{l}\text { Foot propulsion with wings folded. } \\
\text { Depth compresses air to reduce } \\
\text { buoyancy [54]. Intermittent } \\
\text { kicking/gliding for efficiency [75]. }\end{array}$ & $\begin{array}{l}\text { Hydroplaning taxiing } \\
\text { by flapping and foot } \\
\text { propulsion. }\end{array}$ & $\begin{array}{l}\text { Drying period on land [76]. } \\
\text { Foraging upwind of nest for } \\
\text { efficient return flight. }\end{array}$ \\
\hline $\begin{array}{l}\text { Guillemot } \\
\text { (wing propelled) } \\
\text { (Alcidae) }\end{array}$ & $\begin{array}{l}\text { Small wings adapted for } \\
\text { swimming, [51] compensated for } \\
\text { by fast flapping and short } \\
\text { flights [73]. Feathered wings. }\end{array}$ & $\begin{array}{l}\text { Slowed descent and soft, } \\
\text { floating landing. Dive } \\
\text { begins from standstill. }\end{array}$ & $\begin{array}{l}\text { Flapping propulsion, with wings } \\
\text { morphed shorter. [25] Depth } \\
\text { compresses air to reduce buoyancy. }\end{array}$ & $\begin{array}{l}\text { Hydroplaning taxiing } \\
\text { by flapping and foot } \\
\text { propulsion. }\end{array}$ & $\begin{array}{l}\text { Drying period on land [23]. } \\
\text { Foraging upwind of nest for } \\
\text { efficient return flight. }\end{array}$ \\
\hline $\begin{array}{l}\text { Diving Beetle } \\
(\text { Dytiscidae })\end{array}$ & $\begin{array}{l}\text { Insect flight, by rapid flapping } \\
\text { of hind wings. }\end{array}$ & $\begin{array}{l}\text { Dive begins from } \\
\text { standstill. Wings fold } \\
\text { beneath forewings/shell } \\
\text { [77]. }\end{array}$ & $\begin{array}{l}\text { Kicking foot propulsion with wings } \\
\text { folded. Air trapped beneath wings } \\
\text { for breathing. }\end{array}$ & $\begin{array}{l}\text { Flight from standstill } \\
\text { on land. }\end{array}$ & Drying period on land. \\
\hline Robot & Dry Flight & Water Entry & Submerged Movement & Water Exit & Wet Flight \\
\hline $\begin{array}{l}\text { US NRL 'Sea } \\
\text { Robin' }\end{array}$ & $\begin{array}{l}\text { Fuel cell powered propeller } \\
\text { thrust }\end{array}$ & $\begin{array}{l}\text { Landing is final; craft not } \\
\text { designed to relaunch }\end{array}$ & Not Possible & $\begin{array}{l}\text { Discardable torpedo } \\
\text { and deployable wings }\end{array}$ & Not Possible \\
\hline $\begin{array}{l}\text { U Virg. 'Flying } \\
\text { Fish'[70] }\end{array}$ & $\begin{array}{l}\text { Electric propeller with solar } \\
\text { cells. Conventional wing and } \\
\text { tail layout }\end{array}$ & $\begin{array}{l}\text { Slow, autonomous descent. } \\
\text { Landing on twin floats. }\end{array}$ & Not Possible & $\begin{array}{l}\text { Take-off into the wind. } \\
\text { Taxi by hydroplaning } \\
\text { on pontoons }\end{array}$ & $\begin{array}{l}\text { Sensing of weather conditions } \\
\text { to determine appropriate } \\
\text { timing for flight }\end{array}$ \\
\hline $\begin{array}{l}\text { Warrior Aero } \\
\text { 'Gull' }\end{array}$ & $\begin{array}{l}\text { Conventional seaplane layout, } \\
\text { combustion engine, propeller } \\
\text { thrust. }\end{array}$ & $\begin{array}{l}\text { Slow, autonomous descent. } \\
\text { Landing on twin floats. }\end{array}$ & Not Possible & $\begin{array}{l}\text { Slender hull, use of } \\
\text { surface waves as ramps, } \\
\text { pontoons for stability }\end{array}$ & \\
\hline $\begin{array}{l}\text { Beihang U } \\
\text { 'Bionic Gannetl' }\end{array}$ & $\begin{array}{l}\text { Currently a non-flying test } \\
\text { platform }\end{array}$ & $\begin{array}{l}\text { Plunge diving, impact } \\
\text { reduced by variable wing } \\
\text { sweep }\end{array}$ & Passive plunge dive & Not yet possible & $\begin{array}{l}\text { Currently a non-flying test } \\
\text { platform }\end{array}$ \\
\hline
\end{tabular}



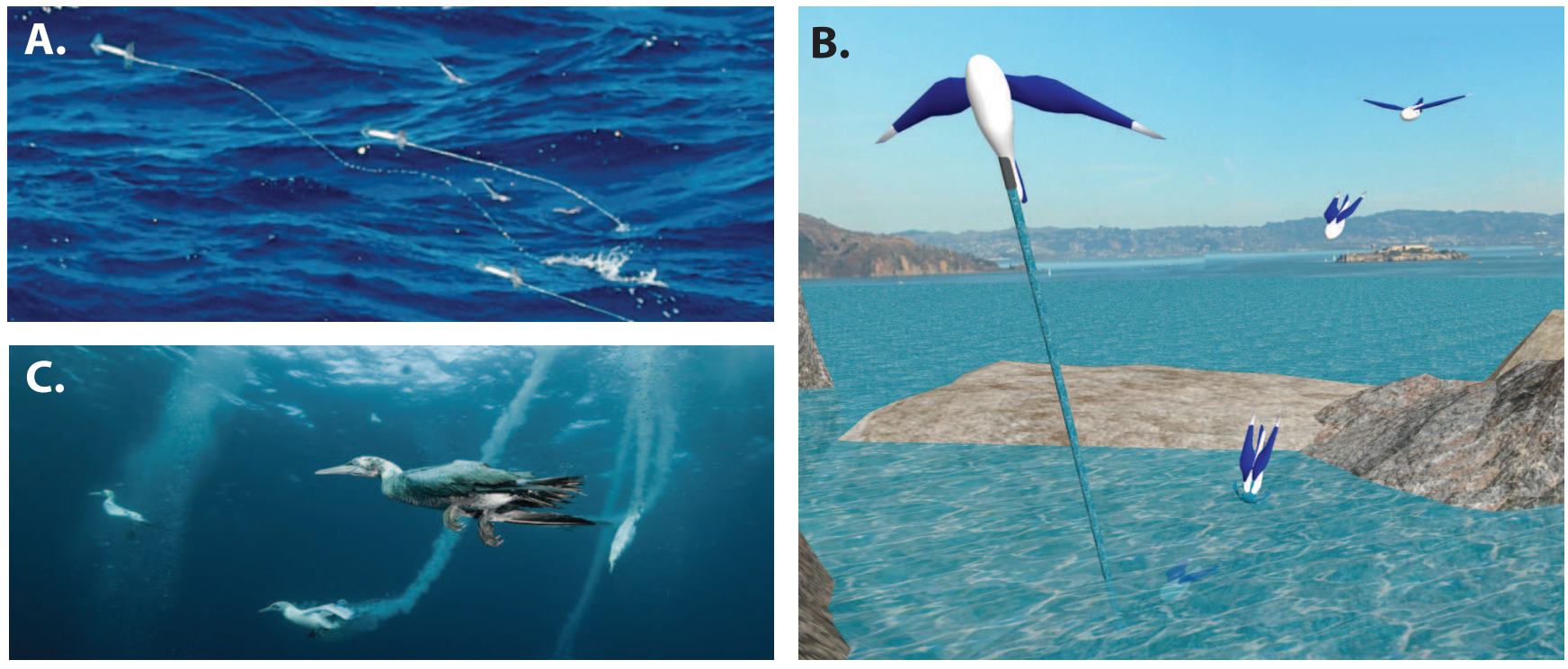

Figure 7: Bioinspired principles for AquaMAV: Plunge diving by gannets (A), Jet propelled take off by squid (B), Plunge diving AquaMAV concept sketch. Images used with permission from: Alexander Safonov (A) and Bob and Deb Hulse (B).

Several military programmes have attempted to create manned submersible aircraft $[78,79]$, but to the authors' knowledge these endeavours have not been completed. Now, the recent shift towards unmanned technology has opened up opportunity for MAV designers. The US Navy Research lab has recently demonstrated the succesful launch of a UAV from a submarine missile tube (figure 6.D). The vehicle (called 'Sea Robin' UAS) uses a discardable tube which brings the vehicle to the surface and provides launching power. At a smaller scale, the ARA Inc. 'TACMAV' can also be deployed from below the surface, by divers using an airbag and compressed gas to launch an MAV (figure 6.E). Both of these vehicles feature deployable wings, but neither have any true aquatic capability and are solely aerial vehicles after takeoff.

\section{Bioinspired Design Principles}

We have summarized the advantages and limitations of several animals and robots with aerial-aquatic capabilities in table 1. While each animal has a distinct set of locomotion modes, several recurring principles can still be identified. For example, all animals employ a form of hydrophobicity to shed water or retain air, most feature some means of buoyancy control and all fold or modify their wing structure when moving in the water.

Here we select from our review several bioinspired design principles, and propose a that a vehicle capable of a jet propelled takeoff, utilising folding wings and able to plunge dive is the best route for realising AquaMAV.

\subsection{Jet Propulsion}

The most challenging part of an aerial-aquatic mission is to re-initiate flight after diving. A vehicle that has been designed for effectively plunging would still need to be minimally buoyant, in order to maximise its dive depth. This would then make a taxiing takeoff near impossible due to the wave drag acting on a vehicle with high displacement.

Flying fish and birds are able to leap directly from the water, and avoid taxiing takeoff complications However, Flying fish must first reach submerged speeds of around 20 body lengths per second. This performance represents an order of magnitude increase over what has been achieved up to this point by biomimetic underwater robots [80], and the power availability of small scale mechanical actuation systems cannot yet match that of bird and fish muscle, without prohibitive sacrifices in frequency response or stroke rate. This will make it hugely difficult to takeoff from the surface of the water by flapping, or biomimetic swimming.

However, water jet propulsion has a very rapid thrust response that is difficult, if not impossible to achieve using propellers, flapping wings or beating tails, and as such is ideal for an impulsive takeoff. Compared to flapping and beating, a full power squid escape jet is also mechanically simple. Importantly, it can continue to produce thrust when clear of the water surface and its associated high drag, unlike fin based water surface jumps, which rely on reaction forces from the surrounding fluid.

The high hydrodynamic drag in water makes it uneconomical to launch directly through the surface, and it is better to accelerate when out of the water. However, leaping directly out of the water is far more robust, 
because it does not rely on a clear expanse of water to accelerate in. In this sense, the flying squid's jet propulsion strategy achieves the best of both worlds, by being able to produce thrust continuously while transitioning between media. This allows an airborne transition stage without the need for the surface taxiing phase required by birds and fish, and when on water, a jet propelled method of launch is also robust to environmental conditions, requiring far less takeoff area than taxiing takeoffs.

One mission an AquaMAV would be uniquely able to perform is the collection and rapid return of a water sample from a hazardous area. Because a sample return mission only requires one takeoff from water, the authors suggest that the energy required to create the jet thrust could come from a 'single-shot' system using compressed air. The propellant water mass can then be collected in situ after diving into the water, to keep flight mass down. While the energy density of such a system would not match that of a combustible rocket, compressed gas is far less hazardous to its environment. Solid rocket fuels are highly controlled by regulations, are difficult to miniaturise [81] and many situations (an oil rig accident, for example) would preclude the use of fire by exploring robots.

\subsection{Wing Folding}

To the best of the author's knowledge, no truly fixedwing animals exist, and wing folding is a feature of most flying creatures, but it becomes more important when locomotion in water is required. Folding wings reduce the vehicle's profile underwater, which can greatly reduce drag. Folded wings also do not have to support as large a hydrodynamic load, which reduces structural requirements, and hence mass. Of the discussed animals, only the guillemot does not fully collapse its wings when in the water, and these birds must still morph their wings into a much lower aspect ratio configuration in order to swim. It is reasonable to then suggest that for an aerial vehicle to submerge, some degree of wing folding will be obligatory.

In robotics, rigid winged underwater gliders do exist, but these craft are too heavy, with wings too small for aerial flight without very high energy density propulsion. Many existing aerial vehicles do employ some kind of morphing wing $[82,83]$, and others feature deployable wings $[3,84]$. However, wing deployment systems are often merely for storage, without the ability to refold, and most morphing concepts only vary the wing geometry slightly. Implementing high performance wing folding into an AquaMAV will require improvements in mechanical design over existing systems.

Flying fish wings are a mechanically attractive inspiration source for deployable wing design. Their wing structure, with rigid battens supporting a flexible mem- brane is reminiscent of recent MAV designs such as [85] and [86]. With regards to deployability, the wings are attractive because they are actuated entirely at their root and do not contain any internal musculature, unlike the wings of birds and bats. This is also the case with insects such as dragonflies and butterflies, considered to be some of the highest performing flying animals.

Flying fish and squid both use dual pairs of wings, which makes their flight very stable [28], and four-winged flying fish have also been observed to glide for greater distances than their two-winged counterparts [29]. Similarly, insects with gliding ability also tend to adopt a biplane configuration, and biplanes have also been shown to have advantages over monoplanes in induced drag and minimum speed for MAVs. The reduction in cruise velocity and resistance to stall would be very advantageous for a momentum-limited takeoff from water and we propose implementing the same layout into an AquaMAV. In flight, if the forward wings could be folded independently of the rearward, this mechanism would also be sufficient to initiate a dive.

\subsection{Plunge Diving}

Among aquatic birds, plung diving birds show the least detriment to their flying ability as a result of adapting for the water, and their landing strategy is robust, simple and does not require additional propulsion or neutral buoyancy to penetrate beneath the water's surface. Especially with regards to mechanical design feasibility, the gannet's plunge dive represents a robust and practical strategy for entry, just as the squid's propulsion system is an effective means of takeoff.

The requirements of accurate control and a large area during taxiing takeoff also exist for a soft water landing. However, plunge diving in the manner of the gannet avoids the complications of soft landings. A plunging vehicle would need minimal landing area, and would need only a GPS waypoint to execute a landing in an area of known bathymetry. Dive velocity can be controlled by varying initial dive height, and will allow accomodation for shallow water. The maximal dive depth will be limited by the structural loads at impact, but the favourable scaling of strength as size is decreased means that MAV size range is better suited to this type of locomotion.

In order to design for effective plunging, folding wings will again be essential, and the gannet's strategy of sweeping wings fully backward at entry is a mechanically simple way to implement this. Such a wing folding system should ideally be designed such that folding the wings shifts the centre of buoyancy aft of the centre of mass. This would that the dive would be stable under buoyancy forces, but at the termination of the dive, unfolding the wings would move the centre of buoyancy forward and orient the vehicle nose up for launch. 
A.

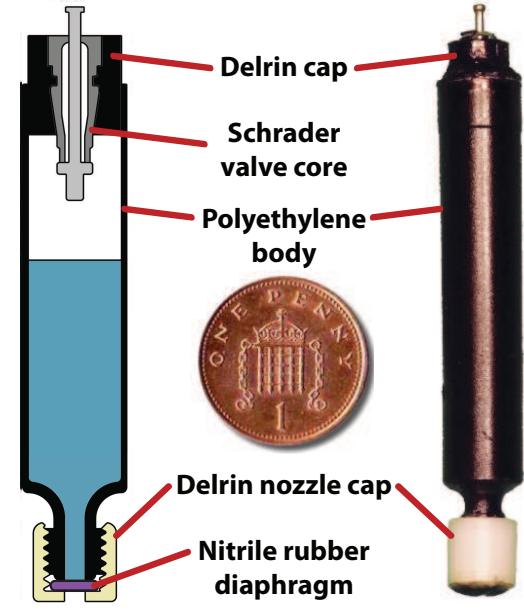

D.

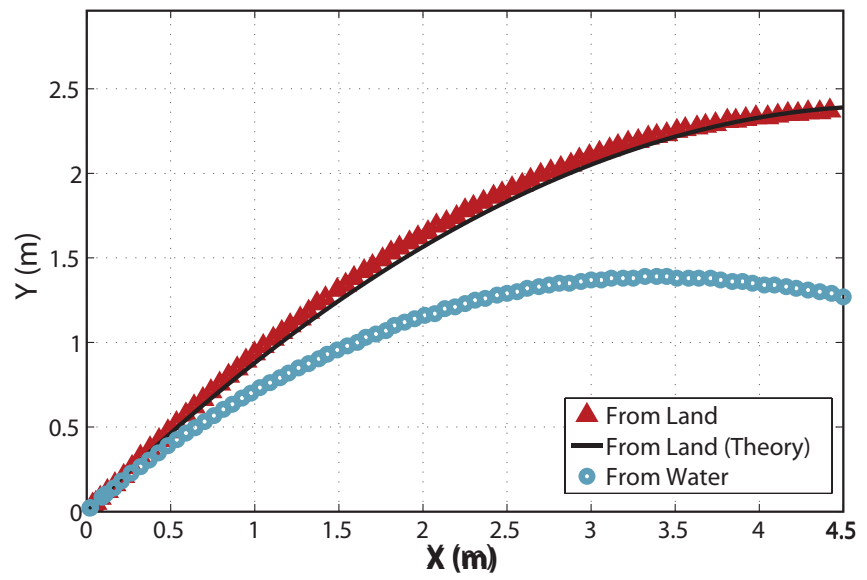

B.

Water Level

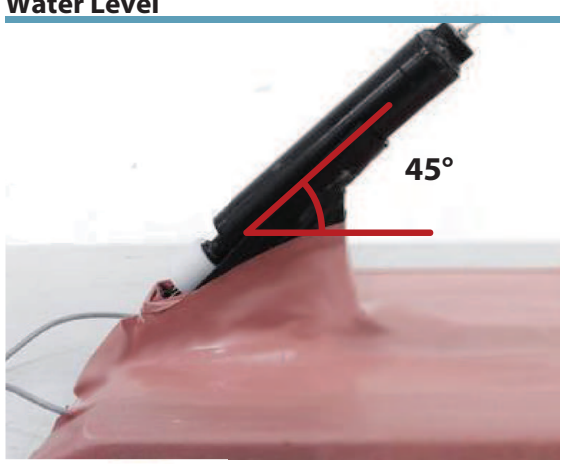

C.

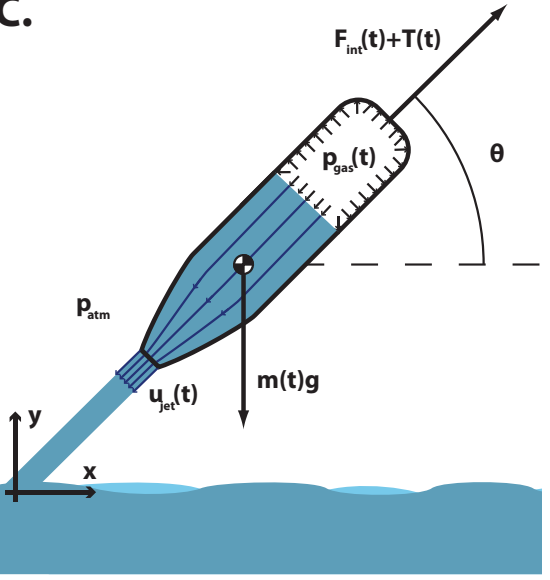

E. E. Thrust

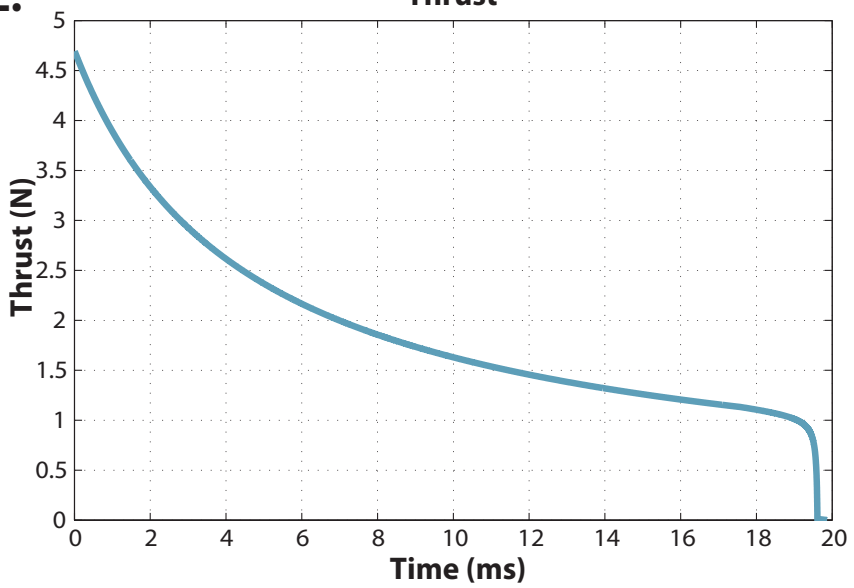

Figure 8: Miniature water jet experiment: Jet Schematic (A); Launch setup, with water level during aquatic launch indicated by blue line (B); Theory nomenclature (C); Tracked launch trajectories (D); Simulated thrust (E).

\section{Proof of concept experiment}

We have proprosed that water jet propulsion would be the best way of launching an AquaMAV without relying on hazardous combustible material. To do validate this proprosal, a simple water jet device has been fabricated.

The jet is a miniaturisation of the ubiquitous 'water rocket', adapted so that it can be actuated electronically. The device contains air and water free to mix, and can be pressurised through a small Schrader ${ }^{\mathrm{TM}}$ valve core. The pressure can be released by bursting a rubber diaphragm using a hot wire (figure 8.A). The plastic jet is not intended to immediately form part of an AquaMAV, but simply to serve as a basis for discussion (the device has immediately obvious shortcomings, such as the inability to launch at shallow angles, due to the lack of separation between water and air).

\subsection{Theoretical Basis}

The incompressibility of water means that the water exit velocity can be calculated using mass continuity and Bernoulli's equation along a streamline running from the air-water interface to the nozzle exit (figure 8.C). Total pressure along this streamline is equal to the instantaneous gas pressure, multiplied by an efficiency factor, $\eta$, that represents the losses due to viscosity as a pressure drop. The gas expansion takes place over a very short time period, meaning that the expansion process can be approximated as adiabatic [87] and the instantaneous gas pressure can be given by the isentropic gas relation (equation 1 ).

$$
\begin{aligned}
& p_{\text {gas }}=p_{0}\left(V_{0} / V\right)^{\gamma} \\
& u_{\text {jet }}=\frac{\dot{V}}{A_{o}}=\sqrt{\frac{2 \eta\left(p_{\text {gas }}-p_{a t m}\right)}{\rho_{w}\left(1-\left(A_{o} / A_{i}\right)^{2}\right)}} \\
& T=2 A_{\text {exit }} \frac{\eta\left(p_{\text {gas }}-p_{\text {atm }}\right)}{1-\left(A_{o} / A_{i}\right)^{2}} \\
& I=\int T+F_{\text {int }} \mathrm{d} t
\end{aligned}
$$

Where $p_{0}$ and $V_{0}$ are the initial gas pressure and volume, $V$ is the gas volume, $A_{i}$ and $A_{o}$ are the nozzle inlet and exit areas and $\rho_{w}$ is the density of water (figure 8.C). The variation of thrust with time can then be 
obtained by numerical integration, which allows launch trajectories to be computed. An additional force term, $F_{\text {int }}(t)$ is the force experienced by the vessel due to the internal fluid mass' acceleration during jetting.

The trajectory is modelled by treating the jet a particle with a drag coefficient of 0.79 (as measured by Bennet [88] for a similarly sized cylinder). If friction from the lubricated launch ramp is ignored, the discharge coefficient is the only unknown in the model, and can be estimated by fitting the modelled and tracked trajectories. This gives a value of 0.89 .

Integrating the propulsive force with respect to time (figure 8.E) gives the total impulse (equation 4). The optimum air-waiter volume fraction can then be found by simulation. A fraction of air of $\beta=36 \%$ was found to give the maximum specific impulse $\left(I / m_{\text {total }}\right)$, and this volume fraction was then used during tests.

\subsection{Experiment}

The jet has an empty mass of 2.55 grams (4.0 grams full), an internal volume of $2.6 \mathrm{ml}$, and is $66 \mathrm{~mm}$ long. The device can be pressured to $9 \mathrm{bar}$, and is the capable of a self propelled jump in air to a vertical height of $4.8 \mathrm{~m}$, equivalent to 72 times its own size.

To test jumping out of water, the jet was launched at a 45 degree angle (figure 8.B) and filmed at $120 \mathrm{fps}$ to track trajectories. Video tracking range was limited by camera field of view, so horizontal jump ranges were measured manually. When launched in air, the jet is able to reach a height of $2.37 \mathrm{~m}$, travelling a horizontal distance of 7.4 (40 times its size). The jet was then immersed in a tray of water, such that the tip was just beneath the water surface (figure 8.D). When launched from the water, additional drag reduced the jump range by $32 \%$ to $5.1 \mathrm{~m},(1.39 \mathrm{~m}$ high).

Table 2: Miniature water jet performance

\begin{tabular}{|l|l|}
\hline Mass (full) & $4.0 \mathrm{~g}$ \\
\hline Mass (empty) & $2.55 \mathrm{~g}$ \\
\hline Peak thrust & $4.5 \mathrm{~N}$ \\
\hline Stored energy & $0.67 \mathrm{~J}$ \\
\hline Energy density & $169 \mathrm{~J} / \mathrm{kg}$ \\
\hline Thrust duration & $20 \mathrm{~ms}$ \\
\hline Average power & $34.1 \mathrm{~W}$ \\
\hline Power density & $8526 \mathrm{~W} / \mathrm{kg}$ \\
\hline Specific impulse & $9.5 \mathrm{~s}$ \\
\hline $\begin{array}{l}\text { Vertical launch } \\
\text { height }\end{array}$ & $4.8 \mathrm{~m}$ \\
\hline
\end{tabular}

\subsection{Scaling of water jet propulsion}

The energy released by the jet is given by integrating the gas pressure from its unexpanded state $\left((1-\beta) V_{t o t}\right)$ to the point at which all water is expelled $\left(V_{t o t}\right)$ (equation
$5)$.

$$
E=\int_{\beta V_{\text {tot }}}^{V_{\text {tot }}} p_{\text {gas }} \mathrm{d} V=\frac{p_{0} V_{0}\left(\beta-\beta^{\gamma}\right)}{1-\gamma}
$$

This gives a scalling of the form $E \propto p V$. For a thin walled cylindrical pressure vessel with a given safety factor, the vessel mass will scale in the same way. This means that the energy density $(E / m)$ of a compressed gas water jet is purely a function of the material's strength to weight ratio. The polyethylene used for the abve jet has a specific ultimate strength of $24 \mathrm{kN} . \mathrm{m} / \mathrm{kg}$, so the use of a high performance material such as carbon fibre $(2300 \mathrm{kN} . \mathrm{m} / \mathrm{kg})$ could potentially increase a water rocket's maximum perfomance a hundredfold. This also means that the jet's energy density is almost entirely independent of both the vessel size and internal gas pressure, a scalability which will be a great asset to AquaMAV design.

While increased pressure will not increase energy density, it will increase the maximum release rate of the energy stored. This is a key benefit of water jet propulsion; while compressed gas lags behind modern batteries in terms of energy density $(0.17 \mathrm{~kJ} / \mathrm{kg}$ for the plastic jet versus $84 \mathrm{~kJ} / \mathrm{kg}$ for a typical $3.5 \mathrm{~g}$ lithium polymer battery), the power that can be developed is much greater. This is critical if a short, impulsive takeoff is to be executed. The unoptimised plastic jet shown here has a power density of around $8 \mathrm{~kW} / \mathrm{kg}$, which already greatly exceeds that of conventional electromechanical systems (around $0.5 \mathrm{~kW} / \mathrm{kg}$ for a typical $10 \mathrm{~g}$ coreless $\mathrm{dc}$ motor and $0.4 \mathrm{~kW} / \mathrm{kg}$ for the aforementioned $3.5 \mathrm{~g}$ lipo battery). It is estimated by Gao et al. [21] that an at-scale biomimetic flying fish robot would need to generate $4 \mathrm{~kW} / \mathrm{kg}$ from its swimming actuators in order to achieve the same launch speeds as a real flying fish. This means jet propulsion is well within the feasibility range for such a system, even if the decreased propulsive efficiency of jet propulsion relative to teleost swimming is considered.

\section{Conclusion}

We have demonstrated the efficacy of our proposed takeoff strategy with a proof of concept jet which can launch itself from both ground and through the air-water boundary. This device is unoptimised, but can be easily modelled, and an optimised jet scaled up to an appropriate size would be sufficient to launch an MAV. The significant challegne is then to produce a folding wing structure capable of sustaining plunge dive loads, without comprimising the aerodynamics of the vehicle in free flight. But, the authors expect that with current advances in materials and manufacturing, such a system can be realised in the near future.

The compromise necessary to locomote effectively in air and water makes it impossible to define a strategy 
that is optimal. However, based on our analysis we are able to make several proposals for robotic AquaMAVs, the implementation of which is ongoing. Such vehicles offer very unique functionality and are already sought after in industry and research. The problem of hybridising aerial and aquatic locomotion has not been well addressed by conventional robot design, but a wealth of successful design principles are used by animals to move in both air and water. By examining and abstracting key biological design principles we will be able to create a new robotic operating paradigm of operation in air and water.

\section{Acknowledgments}

The authors would like to thank the Engineering and Physical Sciences Research Council for their continued funding of this project.

\section{References}

[1] Matthew A. Woodward and M. Sitti. Design of a miniature integrated multi-modal jumping and gliding robot. pages 556-561, 2011.

[2] A. L. Desbiens, M. Pope, F. Berg, Z. E. Teoh, J. Lee, and Cutkosky M. Efficient jumpgliding: Theory and design considerations. IEEE International Conference on Robotics and Automation, 2013.

[3] M Kovač, O Fauria, J-C Zufferey, and D Floreano. The EPFL jumpglider: A hybrid jumping and gliding robot with rigid or folding wings. 2011 IEEE International Conference on Robotics and Biomimetics, pages 1503-1508, 2011.

[4] R Bachmann, F Boria, R Vaidyanathan, P Ifju, and R D Quinn. A biologically inspired micro-vehicle capable of aerial and terrestrial locomotion. Mechanism and Machine Theory, 44:513-526, 2009.

[5] K Peterson, P Birkmeyer, R Dudley, and R S Fearing. A wing-assisted running robot and implications for avian flight evolution. Bioinspiration 83 Biomimetics, 6:046008, 2011.

[6] A Ijspeert, A Crespi, D Ryczko, and J Cabelguen. From swimming to walking with a salamander robot driven by a spinal cord model. Science, 315:1416-20, 2007.

[7] S Floyd, T Keegan, J Palmisano, and M Sitti. A Novel Water Running Robot Inspired by Basilisk Lizards. IEEE/RSJ International Conference on Intelligent Robots and Systems, pages 5430-5436, 2006.

[8] U Saranli, M Buehler, and D E Koditschek. RHex: A Simple and Highly Mobile Hexapod Robot. International Journal of Robotics Research, 20:616-631, 2001.
[9] K Nagatani, S Kiribayashi, Y Okada, K Otake, K Yoshida, S Tadokoro, T Nishimura, T Yoshida, and E Koyanagi. Emergency Response to the Nuclear Accident at the Fukushima Daiichi Nuclear Power Plants using Mobile Rescue Robots. Journal of Field Robotics, 30:44-63, 2013.

[10] R Murphy, E Steimle, C Griffin, C Cullins, M Hall, and K Pratt. Cooperative use of unmanned sea surface and micro aerial vehicles at hurricane wilma. Journal of Field Robotics, 25(3):164-180, 2008.

[11] P Stevenson. Report on Air Launched Autonomous Underwater Vehicles. National Oceanography Centre Research 83 Consultancy Report, 2011.

[12] P Stevenson, S D McPhail, M Tsimplis, and E Higgins. Air Launched Platforms - a new approach for underwater vehicles. IEEE Oceans Conference, pages 1-8, 2009.

[13] F. Shkurti, Anqi Xu, M. Meghjani, J.C. Gamboa Higuera, Y. Girdhar, P. Giguere, B.B. Dey, J. Li, A. Kalmbach, C. Prahacs, K. Turgeon, I. Rekleitis, and G. Dudek. Multi-domain monitoring of marine environments using a heterogeneous robot team. pages $1747-1753,2012$.

[14] M Kovač. The Bioinspiration Design Paradigm: A Perspective for Soft Robotics. Soft Robotics, in press, 2013.

[15] Wei Shyy. Aerodynamics of low Reynolds number flyers, volume 22. Cambridge University Press, 2008.

[16] D. Floreano. Flying insects and robots. Springer Berlin Heidelberg, 2009.

[17] Wei Shyy, Peter Ifju, and Dragos Viieru. Membrane wing-based micro air vehicles. Applied Mechanics Reviews, 58(4):283-301, 2005.

[18] T M Wang, X B Yang, J H Liang, G C Yao, and W D Zhao. Cfd based investigation on the impact acceleration when a gannet impacts with water during plunge diving. Bioinspiration $\&$ Biomimetics, 8(3):036006, 2013.

[19] M-S Park, Y-R Jung, and W-G Park. Numerical study of impact force and ricochet behavior of high speed water-entry bodies. Computers $\&$ Fluids, 32:939-951, 2003.

[20] A Shaw and A Al-Shamma'a. Experimental investigations of electromagnetic wave propagation in seawater. Proceedings of the 36th European Microwave Conference, pages 572-575, 2006.

[21] A Gao and A H Techet. Design considerations for a robotic flying fish. IEEE Oceans Conference, 2011.

[22] T M Williams. Swimming by sea otters: adaptations for low energetic cost locomotion. Journal of Comparative Physiology, 164:815-24, 1989. 
[23] Ví. M Ortega-Jiménez, S Álvarez Borrego, S Arriaga-Ramírez, M Renner, and E S Bridge. Takeoff flight performance and plumage wettability in Cassin's Auklet Ptychoramphus aleuticus, Xantus's Murrelet Synthliboramphus hypoleucus and Leach's Storm-petrel Oceanodroma leucorhoa. Journal of Ornithology, 151:169-177, 2009.

[24] K Kawachi, Y Inada, and A Azuma. Optimal Flight Path of Flying Fish. Journal of Theoretical Biology, 163:145-159, 1993.

[25] R J Lock, R Vaidyanathan, S C Burgess, and J Loveless. Development of a biologically inspired multimodal wing model for aerial-aquatic robotic vehicles through empirical and numerical modelling of the common guillemot, Uria aalge. Bioinspiration ES Biomimetics, 5:046001, 2010.

[26] Robert Dudley, Greg Byrnes, Stephen P Yanoviak, Brendan Borrell, Rafe M Brown, and Jimmy A McGuire. Gliding and the functional origins of flight: biomechanical novelty or necessity? Annu. Rev. Ecol. Evol. Syst., 38:179-201, 2007.

[27] J Davenport. How and why do flying fish fly? Reviews in Fish Biology and Fisheries, 214:184-214, 1994.

[28] H Park and H Choi. Aerodynamic characteristics of flying fish in gliding flight. The Journal of Experimental Biology, 213:3269-79, 2010.

[29] J Davenport. Wing-loading, stability and morphometric relationships in flying fish (Exocoetidae) from the North-eastern Atlantic. Journal of the $M a^{-}$ rine Biological Association of the United Kingdom, $72: 25,2009$.

[30] RT Jones and TA Lasinski. Effect of winglets on the induced drag of ideal wing shapes. NASA Technical Memorandum, 81230(81):70009, 1980.

[31] A Azuma. The Biokinetics of Flying and Swimming. AIAA education series. American Institute of Aeronautics and Astronautics, Inc., 2006.

[32] K L Shephard. Functions for fish mucus. Reviews in Fish Biology and Fisheries, 4:401-429, 1994.

[33] E J Anderson and M E Demont. The locomotory function of the fins in the squid Loligo pealei. Marine and Freshwater Behaviour and Physiology, 38:169-189, 2005.

[34] R K O'Dor, J Stewart, and W Gilly. Squid rocket science: How squid launch into air. Deep Sea Research II, pages 1-6, 2012.

[35] T Kubodera. How far can squid fly out of the water? 2012 Cephalopod International Advisory Council Symposium, 2012.

[36] R K O'dor. The forces acting on swimming squid. Journal of Experimental Biology, 442:421-442, 1988.
[37] K Muramatsu, J Yamamoto, T Abe, K Sekiguchi, N Hoshi, and Y Sakurai. Oceanic squid do fly. $M a-$ rine Biology, 2013.

[38] L Maddock, Q Bone, and J M V Rayner. Mechanics and Physiology of Physiology of Animal Swimming. Cambridge University Press, 1994.

[39] KS Cole and DL Gilbert. Jet propulsion of squid. The Biological Bulletin, 138:245-246, 1970.

[40] S Maciá and M P Robinson. New observations on airborne jet propulsion (flight) in squid, with a review of previous reports. Journal Molluscan Studies, pages 297-299, 2004.

[41] T Aigeldinger and F Fish. Hydroplaning by ducklings: overcoming limitations to swimming at the water surface. The Journal of Experimental Biology, 198:1567-74, 1995.

[42] S Garthe, S Benvenuti, and W A Montevecchi. Pursuit plunging by northern gannets (Sula bassana) feeding on capelin (Mallotus villosus). Proceedings. Biological sciences / The Royal Society, 267:171722, 2000.

[43] P Y Daoust and G V Dobbin. Descriptive anatomy of the subcutaneous air diverticula in the Northern Gannet Morus bassanus. Seabird, 21:64-76, 2008.

[44] Y Ropert-Coudert, D Grémillet, P Ryan, A Kato, Y Naito, and Y Le Maho. Between air and water: the plunge dive of the Cape Gannet Morus capensis. Ibis, 146:281-290, 2003.

[45] J Davenport, R N Hughes, M Shorten, and P S Larsen. Drag reduction by air release promotes fast ascent in jumping emperor penguins - a novel hypothesis. Marine Ecology Progress Series, 430:171$182,2011$.

[46] G Iosilevskii and D Weihs. Speed limits on swimming of fishes and cetaceans. Journal of The Royal Society Interface, 5(20):329-338, 2008.

[47] Y Ropert-Coudert, F Daunt, A Kato, P G Ryan, S Lewis, K Kobayashi, Y Mori, D Grémillet, and S Wanless. Underwater wingbeats extend depth and duration of plunge dives in northern gannets Morus bassanus. Journal of Avian Biology, 40:380-387, 2009.

[48] S Wanless and J D Okill. Body measurements and flight performance of adult and juvenile gannets morus bassanus. Ringing \& Migration, 15:101-103, 1994.

[49] F Richardson. Functional aspects of the pneumatic system of the California brown pelican. The Condor, pages 13-17, 1939.

[50] W L Morgan. Feeding Methods of the Short-tailed Shearwater Puffinus tenuirostris. Emu, 82:226-227, 1982.

[51] J M V Rayner. Pleuston: animals which move in water and air. Endeavour, 1986. 
[52] R J Lock, R Vaidyanathan, S C Burgess, and J Loveless. Development of a biologically inspired multimodal wing model for aerial-aquatic robotic vehicles through empirical and numerical modelling of the common guillemot, Uria aalge. Bioinspiration 83 Biomimetics, 5:046001, 2010.

[53] J R Lovvorn and D R Jones. Biomechanical conflicts between adaptations for diving and aerial flight in estuarine birds. Estuaries and Coasts, 17:62-75, 1994.

[54] F Quintana, R P Wilson, and P Yorio. Dive depth and plumage air in wettable birds: the extraordinary case of the imperial cormorant. Marine Ecology Progress Series, 334:299-310, 2007.

[55] G Ribak. How do cormorants counter buoyancy during submerged swimming? Journal of Experimental Biology, 207:2101-2114, 2004.

[56] J R Lovvorn, G A Liggins, M H Borstad, S M Calisal, and J Mikkelsen. Hydrodynamic drag of diving birds: effects of body size, body shape and feathers at steady speeds. The Journal of Experimental Biology, 204:1547-57, 2001.

[57] R P Wilson, K Hustler, P G Ryan, A E Burger, E Christian, and S Url. Diving Birds in Cold Water: Do Archimedes and Boyle Determine Energetic Costs? The American Naturalist, 140:179-200, 1992.

[58] Robin M Sellers. Wing-spreading behaviour of the cormorant phalacrocorax carbo. Ardea-Wageningen, 83:27-27, 1995.

[59] S Sudo, T Yano, and Y Kan. Swimming behavior of small diving beetles. Journal of Advanced Science, 10:46-49, 2006.

[60] I Ribera and A N Nilsson. Morphometric patterns among diving beetles (Coleoptera: Noteridae, Hygrobiidae, and Dytiscidae). Canadian Journal of Zoology, 73:2343-2360, 1995.

[61] G T Reels and R Dow. Underwater oviposition behavior in two species of Euphaea in Borneo and Hong Kong (Odonata : Euphaeidae). International Journal of Odonatology, 9:197-204, 2006.

[62] P J Mill and R S Pickard. Jet-propulsion in anisopteran dragonfly larvae. Journal of Comparative Physiology, 97:329-338, 1975.

[63] M Burrows and M D Picker. Jumping mechanisms and performance of pygmy mole crickets (Orthoptera, Tridactylidae). The Journal of Experimental Biology, 213:2386-98, 2010.

[64] K H Elliott, R E Ricklefs, A J Gaston, S A Hatch, J R Speakman, and G K Davoren. High flight costs, but low dive costs, in auks support the biomechanical hypothesis for flightlessness in penguins. Proceedings of the National Academy of Sciences, pages $3-7,2013$.
[65] A Fabian, Y F Feng, E Swartz, D Turmer, and $R$ Wang. Hybrid aerial underwater vehicle. MIT Lincoln Lab 2012 SCOPE Projects, 2012.

[66] Jianhong Liang, Xingbang Yang, Tianmiao Wang, Guocai Yao, and Wendi Zhao. Design and experiment of a bionic gannet for plunge-diving. Journal of Bionic Engineering, 10(3):282-291, 2013.

[67] Dana Mackenzie. A flapping of wings. Science, 335(6075):1430-1433, 2012.

[68] K W Moored, F E Fish, T H Kemp, and H BartSmith. Batoid Fishes: Inspiration for the Next Generation of Underwater Robots. Marine Technology Society Journal, 45:99-109, 2011.

[69] John W Gerdes, Satyandra K Gupta, and Stephen A Wilkerson. A review of bird-inspired flapping wing miniature air vehicle designs. ASME, 2012.

[70] R D Eubank. Autonomous Flight, Fault, and Energy Management of the Flying Fish Solar-Powered Seaplane.

[71] W Shyy, Y Lian, J Tang, D Viieru, and H Liu. Aerodynamics of low Reynolds number flyers. Cambridge University Press, 2007.

[72] E J Anderson and M Grosenbaugh. Jet flow in steadily swimming adult squid. The Journal of Experimental Biology, 208:1125-46, 2005.

[73] L B Spear and D G Ainley. Flight behaviour of seabirds in relation to wind direction and wing morphology. Ibis, 139:221-233, 1997.

[74] Y Y Watanabe, A Takahashi, K Sato, M Viviant, and C-A Bost. Poor flight performance in deepdiving cormorants. The Journal of Experimental Biology, 214:412-21, 2011.

[75] G Ribak, D Weihs, and Z Arad. Submerged swimming of the great cormorant Phalacrocorax carbo sinensis is a variant of the burst-and-glide gait. The Journal of Experimental Biology, 208:3835-49, 2005.

[76] T R Cook and G Leblanc. Why is wing-spreading behaviour absent in blue-eyed shags? Animal Behaviour, 74:649-652, 2007.

[77] Azhar Muhammad, Quoc Viet Nguyen, Hoon Cheol Park, Do Y Hwang, Doyoung Byun, and Nam Seo Goo. Improvement of artificial foldable wing models by mimicking the unfolding/folding mechanism of a beetle hind wing. Journal of Bionic Engineering, 7:134-141, 2010.

[78] J Eastgate and R Goddard. Submersible Aircraft Concept Design Study. Naval Surface Warfare Center Technical Report, 2011.

[79] B D Reid. The Flying Submarine: The Story of the Invention of the Reid Flying Submarine, RFS-1. Eagle Editions, 2004.

[80] W Chu, K Lee, S Song, M Han, J Lee, H Kim, M Kim, Y Park, K Cho, and S Ahn. Review of 
biomimetic underwater robots using smart actuators. International Journal of Precision Engineering and Manufacturing, 13:1281-1292, 2012.

[81] M Kovač, M Bendana, R Krishnan, and J Burton. Multi-stage micro rockets for robotic insects. roboticsproceedings.org.

[82] D Grant, M Abdulrahim, and R Lind. Design and analysis of biomimetic joints for morphing of micro air vehicles. Bioinspiration 6 Biomimetics, 5:045007, 2010.

[83] M Abdulrahim, G Ivey, and R Lind. Flight testing a micro air vehicle using morphing for aeroservoelastic control. AIAA Structures, Structural Mechanics, 2004.

[84] S D Landon. Development of Deployable Wings for Small Unmanned Aerial Vehicles Using Compliant
Mechanisms. MSc Theis, Brigham Young University, 2007.

[85] A Maqsood, Z Zeng, and T H Go. Flexible Wing Aerodynamics at Low Reynolds Numbers. Proceedings of the 28th International Congress of the Aeronautical Sciences, pages 1-7, 2012.

[86] W Shyy, P Ifju, and D Viieru. Membrane WingBased Micro Air Vehicles. Applied Mechanics Reviews, 58:283, 2005.

[87] Joseph M Prusa. Hydrodynamics of a water rocket. SIAM review, 42(4):719-726, 2000.

[88] HC Bennet-Clark and GM Alder. The effect of air resistance on the jumping performance of insects. The Journal of Experimental Biology, 82(1):105$121,1979$. 